\title{
Research on the Relationships Among Customer Participation, Knowledge Integration and New Product Development Performance
}

\author{
Yong Cao, Hongzhi Zhou* \\ School of Management, Wuhan Textile University, Wuhan, China \\ Email address: \\ caoyong@mail.hust.edu.cn (Yong Cao),676801930@qq.com (Hongzhi Zhou) \\ ${ }^{*}$ Corresponding author
}

\section{To cite this article:}

Yong Cao, Hongzhi Zhou. Research on the Relationships Among Customer Participation, Knowledge Integration and New Product Development Performance. International Journal of Economics, Finance and Management Sciences. Vol. 9, No. 1, 2021 , pp. $38-45$. doi: 10.11648/j.ijefm.20210901.15

Received: January 18, 2021; Accepted: March 1, 2021; Published: March 3, 2021

\begin{abstract}
Under the background of the knowledge economy, business managers have gradually realized that improving innovation performance requires breaking organizational boundaries to obtain knowledge, technology and other resources from the outside. As one of the important external subjects of new product development (NPD), customers actively participate in NPD activities become an effective way to acquire customer knowledge. However, there are still divergent studies on the effect of customer participation (CP) on NPD performance. In view of this, this research explores the relationship between customer participation, knowledge integration, absorptive capacity, and NPD performance, and this paper empirically studied the influence of CP on NPD performance through a large sample questionnaire survey, and focused on the analysis of the mediating role of knowledge integration and the moderating effect of absorptive capacity. The results show that CP has a significant positive effect on knowledge integration and NPD performance; knowledge integration has mediating effect between CP and NPD performance; Absorptive capacity positively moderates the relationship between $\mathrm{CP}$ and knowledge integration, but has no significant moderating effect on CP and NPD performance. From the perspective of knowledge management, this study links customer participation with NPD performance, and the research results not only have important theoretical implications for the in-depth study of customer participation, NPD performance, knowledge integration and absorptive capacity, but also have important practical significance to improve the success rate of NPD and promote high-quality development.
\end{abstract}

Keywords: Customer Participation, Knowledge Integration, Absorptive Capacity, NPD Performance

\section{Introduction}

With the rapid development of Internet technology and the advent of the knowledge economy era, it is difficult for any enterprise to achieve effective innovation by relying only on internal resources. Therefore, enterprises need to break organizational boundaries to continuously absorb and utilize external knowledge resources to gain sustainable competitive advantages [1]. As one of the important external resources of enterprises, customer participation has an important impact on new product development (NPD) performance, but there are still divergent studies on how customer participation affects the NPD performance of enterprises [2]. Therefore, it is of great significance to further explore the impact of customer participation on NPD performance and its mechanism of action to enhance the innovation capability of high-tech enterprises and promote their high-quality development.

Knowledge management theory suggests that an enterprise's innovation performance depends not only on the knowledge acquired by the enterprise, but also on the ability to transform knowledge into innovative outputs [3]. When customers participate in NPD activities, enterprises need to synergize customer knowledge with internal organizational knowledge, so that heterogeneous knowledge from different sources can intermingle and knowledge integration can be effectively realized to better respond to changing market demands and thus promote effective development of new products, which indicates the mediating role of knowledge 
integration in the process of customer participation affecting NPD performance [4]. At the same time, to maximize the absorption and utilization of knowledge owned by customers, enterprises must also have good absorptive capacity, that is, the ability to acquire, absorb and utilize new knowledge from external sources. Good absorptive capacity will strengthen the enterprise's awareness, absorption and transformation of customer knowledge, and create new knowledge after integrating with internal knowledge, helping the enterprise to continuously update the knowledge base in a dynamic environment, expand the breadth and depth of the knowledge base and develop newer and better products with faster speed and higher quality [5], further enhancing NPD performance. Based on the theoretical basis of the relationship between customer participation, knowledge integration, absorptive capacity and NPD performance, this paper empirically investigates the mechanism of customer participation affecting NPD performance, focusing on the mediating role of knowledge integration and the moderating effect of absorptive capacity, and then reveals the paths and boundary conditions of customer participation affecting NPD performance, taking high-tech enterprises as the target. The findings not only expand the theoretical basis of the relationship between customer participation and NPD performance, but also have important implications for providing realistic guidance on the effective management of NPD activities and enhancing the innovation success of high-tech enterprises in China.

\section{Literature Review and Hypotheses}

\subsection{Customer Participation \& NPD Performance}

Customer participation refers to the process of interaction between product developers and existing or potential customers at different stages of development in the new product development (NPD) process [6]. According to the resource-dependent theory, customer demand and previous consumption experience are the key resources for the successful development of new products. Customer participation helps R\&D teams to acquire new knowledge, skills, technology and capital, which play an important role in accelerating innovation, improving product quality and increasing market acceptance for companies [7]. Carlson et al [8] argued that enterprises can establish good customer relationships with customers to obtain customer knowledge resource input and develop products that better meet customer needs, thus greatly improving market competitiveness. In addition, Zhang \& Liao [9] explored the positive impact of customer participation on product novelty and speed to market from a knowledge sharing perspective, arguing that customer knowledge is a unique and inimitable innovation resource, and customer participation in R\&D innovation activities can promote deep knowledge sharing and thus enhance corporate innovation performance. In summary, customer participation not only enables companies to obtain timely knowledge from customer feedback and develop products that better meet market demand, but also promotes the construction of good interactive relationships between customers and companies and improves market recognition, thus reducing market risk and improving NPD performance. Based on the above analysis, this paper proposes the following hypotheses:

H1: Customer participation has a positive impact on NPD performance.

\subsection{The Mediating Role of Knowledge Integration}

As a process of recognizing, integrating, transforming and reconstructing knowledge of different forms, knowledge integration plays an important role in improving the efficiency of knowledge management of enterprises, and is a key link to promote the establishment of close knowledge connection among various innovation entities and improve NPD performance [10]. Grant [11] argued that knowledge integration capability is closely related to the existing knowledge experience of enterprises, and this capability can be enhanced with the continuous accumulation of learning from internal and external knowledge resources, and by integrating knowledge of different structures and levels, enterprises can provide a knowledge base for NPD and thus improve their innovation capability. On the one hand, customer participation increases the diversity of enterprise knowledge resources, and the positive interaction between customers and internal employees of enterprises is conducive to reducing the influence of knowledge asymmetry, maximizing the knowledge sharing and reorganization and application between customers and employees, reducing the difficulty of knowledge integration and improving the efficiency of knowledge integration [4]. On the other hand, knowledge integration promotes a high degree of integration of internal and external knowledge in the organization, which can maximize the business value embedded in knowledge and thus contribute to the improvement of NPD performance [10].

Based on the above analysis, this study suggests that knowledge integration has a bridging role in the mechanism of action of customer participation in influencing NPD performance. First of all, customer participation is an important way to effectively improve enterprise performance under the knowledge integration mechanism. Through knowledge integration, enterprises can deeply excavate a large amount of fragmented and fuzzy customer knowledge and improve the degree of understanding and quality of absorption of customer knowledge to ensure that it can be effectively used in product or service development activities [4]. Secondly, knowledge integration is also an effective means to improve the utilization of customer knowledge and avoid R\&D risks in the process of customer participation affecting NPD performance. Through the integration of new and old internal and external knowledge, enterprises can increase the possibility of recombination of knowledge elements and form enterprise-specific tacit knowledge, thereby promoting the establishment of sustainable competitive advantages [12]. And the stronger the ability of knowledge integration is, the higher the efficiency of knowledge circulation in an organization will be, which is conducive to the accurate evaluation and utilization of the acquired knowledge by an 
enterprise, thus effectively reducing the uncertainty in the NPD process and improving the enterprise performance [13]. That is, customer participation can provide more knowledge sources for product innovation, and knowledge integration can help enterprises to explore, absorb and use more redundant new knowledge, increase knowledge reserves, and then improve NPD performance. Therefore, the following hypotheses are proposed in this paper.

$\mathrm{H} 2$ : Knowledge integration plays a mediating role in the relationship between customer participation and NPD performance.

\subsection{Moderating Role of Absorption Capacity}

Cohen \& Levintha [14] pointed out that absorptive capacity is an enterprise's ability to identify, digest and utilize external heterogeneous knowledge for commercialization. Flor et al [15] showed that absorptive capacity affects the efficiency of a firm's transformation and utilization of externally acquired knowledge sources, which helps to enhance the organization's knowledge acquisition and processing capabilities, which in turn has an impact on innovation performance. This suggests that absorptive capacity plays an important role in the mechanism of achieving NPD performance in firms.

$\mathrm{Li}$ and Yang [3] showed that absorptive capacity affects the integration ability of enterprises to external knowledge. The stronger the absorptive capacity is, the more conducive it is to promote the flow and diffusion of knowledge inside an enterprise, and better promote the improvement of the level of knowledge integration. In the era of knowledge economy, the development of enterprises needs to continuously acquire external knowledge to enhance innovation ability, and customer participation can provide valuable knowledge for enterprises, but it requires internal $R \& D$ personnel of the organization to identify, absorb, transform and integrate and apply it in order to better play its value [16]. In the process of customers' participation in NPD activities, enterprises with strong absorption ability have higher efficiency in acquiring, organizing and transforming customer knowledge, and customer knowledge can be quickly transformed into the knowledge required for NPD. So repeatedly, the knowledge system owned by enterprises gradually expands, which not only increases the depth and breadth of the enterprise knowledge base, but also realizes the reorganization of internal and external knowledge resources of enterprises, and promotes the transformation and effective Integration. That is, the absorptive capacity has a moderating effect on the relationship between knowledge integration and customer participation.

A study by Dai et al [17] showed that absorptive capacity positively moderates the relationship between customer participation and innovation performance, and enterprises can use their strong absorptive capacity to dig deep into customer knowledge and provide necessary knowledge sources for NPD. From the perspective of knowledge management, under the limited resource environment, enterprises with stronger absorptive capacity can acquire, absorb and utilize customer knowledge more effectively and tap into valuable knowledge to enrich the original knowledge base, accelerate the formation of ideas and the NPD process, and thus improve the innovation capability of enterprises [13]. From the perspective of technological capabilities, absorptive capacity is an important tool for acquiring and processing customer knowledge when customers are involved in NPD activities. The stronger the absorptive capacity, the richer the customer knowledge acquired by the organization and the more effective it is in transforming customer knowledge into innovative outputs, thus enhancing the competitiveness of the firm and improving NPD performance [16]. That is, absorptive capacity has a moderating effect on the relationship between customer participation and NPD performance. Therefore, this paper proposes the following hypothesis:

H3: Absorptive capacity positively moderates the relationship between customer participation and knowledge integration.

H4: Absorptive capacity positively moderates the relationship between customer participation and NPD performance.

Therefore, we put forward the conceptual model, as indicated in Figure 1.

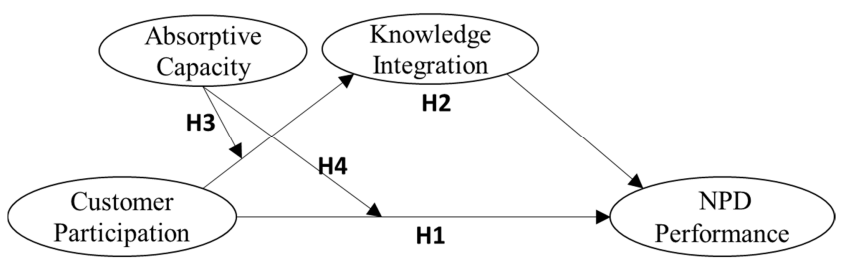

Figure 1. Research concept model.

\section{Method}

\subsection{Sampling and Data Collection}

In this study, large sample questionnaires were used to collect data and high-tech enterprises in the Wuhan-China Optics Valley National Innovation Demonstration Zone were selected as respondents. In order to ensure the scientific validity and rationality of the questionnaire, the design of the questionnaire referred to authoritative journals at home and abroad and mature scale with high citation rate. In combination with the characteristics of this study and the innovative characteristics of employees of high-tech enterprises in China, localization adjustment was carried out, and the final questionnaire was formed after multiple rounds of optimization by means of expert consultation, visit and research. The data collection took five months and was mainly collected through two channels: (1) on-site visits to sample companies and questionnaires distributed to their employees after obtaining permission from the contact person of the companies; (2) Based on the social relations of the project team members, the employees of the company they work for were investigated by E-mail. A total of 425 questionnaires were issued and 348 were recovered. After eliminating the questionnaires with missing items and obvious problems, 317 valid questionnaires were obtained, with an effective recovery rate of $74.6 \%$. The respondents of this study are mainly between $26-45$ years old $(74 \%)$, with bachelor or master 
degree or above (87\%), and frontline employees in $R \& D$, design and management positions, who are more aware of NPD activities. And the sample companies are mostly small and medium-sized private and state-owned enterprises within 10 years of establishment, which are rich in R\&D and innovation activities and have different degrees of external cooperation experience, so the sample of this study is more representative.

\subsection{Measurement Scales}

In this study, customer participation, knowledge integration, absorptive capacity and NPD performance were measured using a seven-point Likert scale, where "1" means "strongly disagree" and "7" means "strongly agree". The measurement of customer participation, drawing on the scales of Morgan et al [7] and Yi \& Gong [18], was designed with nine questions in three dimensions: information sharing, responsible behavior and interpersonal interaction. The measurement of knowledge integration was designed with four questions based on the studies of Eslami et al [19] and Salunke et al [10]. For the measurement of absorptive capacity, four items were designed by referring to the definition by Cohen \& Levinthal [14] and the study by Flor et al [15]. The measurement of NPD performance refers to the results of Natti et al [5] and Jian et al
[16], and 4 items are designed in combination with the background of this research. In addition, this study selected firm size and firm age as the control variables, which have been shown to have an impact on innovation performance.

\subsection{Scale Reliabilities and Validities}

In this study, SPSS22.0 was used to test the reliability of variables such as customer participation, knowledge integration, absorptive capacity and NPD performance, the results are shown in Table 1 , and all constructs have Cronbach's alpha values higher than 0.7 , indicating that the scale has a high internal consistency. Second, construct validity is established using confirmatory factor analysis, the values for the model-fit indices $\left(\chi^{2} / \mathrm{df}=2.21, \mathrm{GFI}=0.92\right.$, $\mathrm{AGFI}=0.91, \mathrm{CFI}=0.98, \mathrm{IFI}=0.97$, $\mathrm{RMSEA}=0.05)$ indicate that the study has good structural validity. And Table 1 shows that the factors loadings of each variable are all higher than 0.5 , while the CR values are all higher than 0.8 and the AVE values are all higher than 0.5 , indicating that the convergent validity is satisfactory. In addition, Table 2 shows that the absolute value of the correlation coefficients between the variables is not higher than 0.6 and the square root of the AVE are larger than any other corresponding row and column entry, which means that the variables have good discriminate validity.

Table 1. Scale reliabilities and validities tests.

\begin{tabular}{|c|c|c|c|c|c|}
\hline Construct & Item code & Factor loading & Cronbach's alpha & $\mathbf{C R}$ & AVE \\
\hline \multirow{3}{*}{ Information sharing (IS) } & IS1 & 0.80 & \multirow{3}{*}{0.76} & \multirow{3}{*}{0.86} & \multirow{3}{*}{0.68} \\
\hline & IS2 & 0.84 & & & \\
\hline & IS3 & 0.83 & & & \\
\hline \multirow{3}{*}{ Responsible behaviour (RB) } & $\mathrm{RB} 1$ & 0.83 & \multirow{3}{*}{0.73} & \multirow{3}{*}{0.85} & \multirow{3}{*}{0.66} \\
\hline & RB2 & 0.78 & & & \\
\hline & RB3 & 0.82 & & & \\
\hline \multirow{2}{*}{ Interpersonal interaction (PI) } & PI1 & 0.86 & \multirow{2}{*}{0.82} & \multirow{2}{*}{0.90} & \multirow{2}{*}{0.74} \\
\hline & PI3 & 0.83 & & & \\
\hline \multirow{4}{*}{ Knowledge integration (KI) } & KI1 & 0.74 & \multirow{4}{*}{0.74} & \multirow{4}{*}{0.84} & \multirow{4}{*}{0.61} \\
\hline & $\mathrm{KI} 2$ & 0.78 & & & \\
\hline & $\mathrm{KI} 3$ & 0.72 & & & \\
\hline & KI4 & 0.83 & & & \\
\hline \multirow{2}{*}{ Absorptive capacity (AC) } & $\mathrm{AC} 1$ & 0.87 & \multirow{2}{*}{0.79} & \multirow{2}{*}{0.91} & \multirow{2}{*}{0.70} \\
\hline & $\mathrm{AC} 2$ & 0.85 & & & \\
\hline \multirow{4}{*}{ NPD performance (NPDP) } & NPDP1 & 0.77 & \multirow{4}{*}{0.75} & \multirow{4}{*}{0.88} & \multirow{4}{*}{0.65} \\
\hline & NPDP2 & 0.78 & & & \\
\hline & NPDP3 & 0.83 & & & \\
\hline & NPDP4 & 0.85 & & & \\
\hline
\end{tabular}

Notes: All factor loadings are significant

Table 2. Descriptive statistics and correlations.

\begin{tabular}{lllllllll}
\hline Variables & Mean & SD & $\mathbf{1}$ & $\mathbf{2}$ & $\mathbf{3}$ & $\mathbf{4}$ & $\mathbf{5}$ & $\mathbf{6}$ \\
\hline IS & 4.50 & 0.96 & $\mathbf{0 . 8 2}$ & & & & \\
RB & 4.40 & 0.93 & $0.53^{* *}$ & $\mathbf{0 . 8 1}$ & & & \\
PI & 4.49 & 0.87 & $0.59^{* *}$ & $0.58^{* *}$ & $\mathbf{0 . 8 6}$ & & \\
KI & 4.53 & 0.84 & $0.57^{* *}$ & $0.54^{* *}$ & $0.56^{* *}$ & $\mathbf{0 . 7 8}$ & & \\
AC & 4.45 & 0.79 & $0.27^{* *}$ & $0.32^{* *}$ & $0.42^{* *}$ & $0.52^{* *}$ & $\mathbf{0 . 8 4}$ & \\
NPDP & 4.49 & 0.80 & $0.35^{* *}$ & $0.44^{* *}$ & $0.46^{* *}$ & $0.57^{* *}$ & $0.60^{* *}$ & $\mathbf{0 . 8 1}$ \\
Firm size & 2.13 & 0.88 & 0.04 & -0.01 & 0.01 & -0.03 & 0.05 & -0.06 \\
Firm age & 2.05 & 0.87 & -0.10 & -0.14 & $-0.19^{* *}$ & -0.11 & -0.02 & 0.05 \\
\hline
\end{tabular}

Notes: ${ }^{\mathrm{p}}<0.05 ; * * \mathrm{p}<0.01 ; * * * \mathrm{p}<0.001$; Bold elements on the diagonal indicate the square root of the AVE 


\section{Result}

This study used hierarchical regression analysis to test the effect of customer participation on NPD performance, the mediating role of knowledge integration in this influence mechanism, and the moderating effect of absorptive capacity. Before performing the regression analysis, the variables were tested for multicollinearity, and the VIF values for all variables were between 1 and 3 , indicating that no serious multicollinearity existed. The regression results are shown in Table 3.

\subsection{Main and Mediating Effect Test}

Firstly, in order to test the effect of customer participation on NPD performance, regression models 1 and 2 are constructed with NPD performance as the dependent variable, and Table 3 shows that the explanatory power of model 2 increases to $23.7 \%$ with the addition of independent variables on the basis of model 1 , and the regression coefficient of customer participation on NPD performance is $0.51(\mathrm{p}<0.001)$, which means that customer participation has a significant positive effect on NPD performance. So H1 is supported.

Secondly, in order to test the mediating effect of knowledge integration, Model 3, Model 4, Model 7 and Model 8 were constructed on the basis of the original model. From the regression results, model 8 shows that there is a significant positive effect of customer participation on knowledge integration $(\beta=0.71, p<0.001)$, and knowledge integration has a significant effect on NPD performance $(\beta=0.59, \mathrm{p}<0.001)$. From Model 4, it is found that the Adj-R2 value changes from 0.237 to 0.341 after the introduction of both independent and mediating variables, the explanatory power of the model is effectively improved, and the coefficient of the effect of knowledge integration on NPD performance was 0.46 , while the regression coefficient of the independent variable changed from $0.51(\mathrm{p}<0.001)$ to $0.18(\mathrm{p}<0.05)$ compared to Model 2, but still significant, so it is believed that knowledge integration plays a partially mediating role between customer participation and NPD performance. So H2 is supported well.

Table 3. Results of hierarchical regression analysis.

\begin{tabular}{|c|c|c|c|c|c|c|c|c|c|c|}
\hline \multirow{2}{*}{ Variables } & \multicolumn{6}{|c|}{ NPD Performance } & \multicolumn{4}{|c|}{ Knowledge Integration } \\
\hline & Model 1 & Model 2 & Model 3 & Model 4 & Model 5 & Model 6 & Model 7 & Model 8 & Model 9 & Model 10 \\
\hline Firm Size & 0.04 & 0.05 & 0.03 & 0.03 & 0.08 & 0.08 & 0.03 & 0.05 & 0.07 & 0.05 \\
\hline Firm Age & 0.05 & $0.12^{*}$ & 0.11 & $0.13^{*}$ & 0.10 & 0.09 & 0.11 & 0.01 & 0.02 & 0.01 \\
\hline $\mathrm{CP}$ & & $0.51^{* * *}$ & & $0.18^{*}$ & $0.31^{* * *}$ & $0.27^{* * *}$ & & $0.71^{* * *}$ & $0.52^{* * *}$ & $0.49^{* * *}$ \\
\hline $\mathrm{KI}$ & & & $0.59^{* * *}$ & $0.46^{* * *}$ & & & & & & \\
\hline $\mathrm{AC}$ & & & & & $0.50^{* * *}$ & $0.49^{* * *}$ & & & $0.47^{* * *}$ & $0.42^{* * *}$ \\
\hline $\mathrm{CP} \times \mathrm{AC}$ & & & & & & -0.11 & & & & $0.19^{*}$ \\
\hline Adj-R ${ }^{2}$ & 0.01 & 0.23 & 0.32 & 0.34 & 0.45 & 0.45 & -0.01 & 0.49 & 0.58 & 0.61 \\
\hline $\mathrm{F}$ & 0.29 & $14.68^{* * *}$ & $22.47^{* * *}$ & $19.81^{* * *}$ & $29.71^{* * *}$ & $25.68^{* * *}$ & 0.78 & $43.53^{* * *}$ & $63.34^{* * *}$ & $73.45^{* * *}$ \\
\hline
\end{tabular}

\subsection{Moderating Effect Test}

Finally, test the moderating effect of absorptive capacity. In order to increase the explanatory significance of the coefficients of the equations, the values of the independent and moderating variables were centered before the regression analysis, and the interaction term was generated from the product of the centered variables. It can be seen from Table 3 that the interaction term between customer participation and absorptive capacity has a significant influence on knowledge integration $(\beta=0.19, p<0.05)$, indicating that absorptive capacity positively moderates the relationship between customer participation and knowledge integration. To further verify the interaction between customer participation and absorptive capacity, the absorptive capacity is added and subtracted by one standard deviation from the mean value and a moderating effect plot is made. As shown in Figure 2, the regression lines of customer participation on knowledge integration have different slopes under different levels of absorptive capacity, and the slope is significantly larger under high absorptive capacity level, i.e., the positive effect of customer participation on knowledge integration is stronger under high absorptive capacity level, and hypothesis 3 is verified. However, the interaction term coefficient of customer participation and absorptive capacity in Model 6 is -0.11 $(\mathrm{p}<0.1)$, and through further simple slope analysis (Figure 2$)$, it is found that high absorptive capacity will weaken the effect of customer participation on NPD performance. That is, as the level of corporate absorptive capacity increases, the role of customer participation in promoting NPD performance gradually decreases. $\mathrm{H} 4$ is not supported.

\subsection{Robustness Test}

In order to verify the reliability and robustness of the conclusions, refer to the study of Preacher \& Hayes [20] and use the bootstrapping method to test the direct effect of customer participation and NPD performance, the mediating effect of knowledge integration and the moderating effect of absorptive capacity. Process was used to analyze the relevant data with a sample size of 5000 and a Bootstrap confidence interval of $95 \%$. First, Model 4 was selected and run in the Process plug-in in SPSS to test the relationship between customer participation, knowledge integration, and NPD performance while controlling for firm size and firm age. The upper and lower limits of Bootstrap 95\% confidence intervals for the direct effect of customer participation on NPD performance and the mediating effect of knowledge integration do not contain 0 (Table 4), indicating that the direct 
effect of customer participation on NPD performance and the mediating effect of knowledge integration in the relationship between them are significant. Hypothesis 1 and Hypothesis 2 are again verified. Second, model 8 was selected and run in Process, and the results showed that the interactive items of customer participation and absorptive capacity have a significant impact on knowledge integration and NPD performance. As shown in Table 5, the stronger the absorptive capacity, the greater the effect of customer participation on knowledge integration, indicating that absorptive capacity positively moderates the relationship between customer participation and knowledge integration, and Hypothesis 3 holds. However, the effect of customer participation on NPD performance tends to decrease gradually at the three levels of absorptive capacity, that is, the effect of customer participation in R\&D activities on enhancing NPD performance gradually decreases as the absorptive capacity of enterprises increases. Hypothesis 4 is not supported.

In summary, consistent results were obtained using different methods to test the research hypotheses, indicating that the findings are well robust.

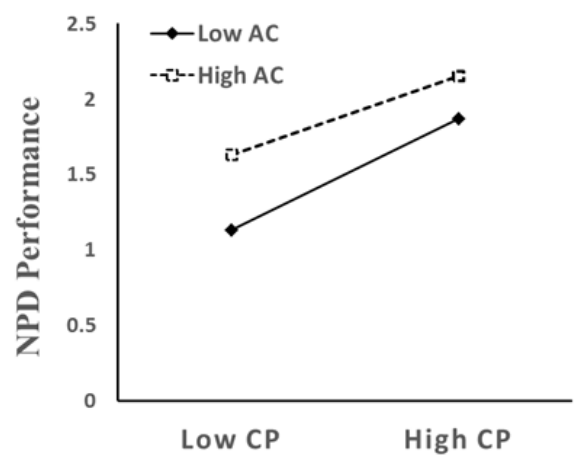

Figure 2. Moderating effect of absorptive capacity.

Table 4. Decomposition of total effect, direct effect and mediating effect.

\begin{tabular}{llllll}
\hline & Effect & Boot SE & Boot LLCI & Boot ULCI & Relative Effect \\
\hline Direct Effect & 0.182 & 0.102 & 0.019 & 0.381 & $35.69 \%$ \\
Indirect Effect & 0.328 & 0.071 & 0.192 & 0.471 & $64.31 \%$ \\
Total Effect & 0.510 & 0.067 & 0.373 & 0.647 & \\
\hline
\end{tabular}

(Note: Boot SE, Boot LLCI, Boot ULCI refers to the standard error, lower and upper limits of the $95 \%$ confidence interval estimated by the percentile Bootstrap method of bias correction, respectively.)

Table 5. Effect of CP on KI and NPDP at different levels of absorptive capacity.

\begin{tabular}{llllll}
\hline Path & Absorptive Capacity & Coefficient & Boot SE & Boot LLCI & Boot ULCI \\
\hline \multirow{2}{*}{$\mathrm{CP} \rightarrow \mathrm{NPDP}$} & M-1SD & 0.331 & 0.090 & 0.153 & 0.508 \\
& M & 0.222 & 0.083 & 0.058 & 0.387 \\
& M+1SD & 0.115 & 0.112 & -0.106 & 0.336 \\
$\mathrm{CP} \rightarrow \mathrm{KI}$ & M-1SD & 0.116 & 0.053 & 0.122 & 0.220 \\
& M & 0.187 & 0.036 & 0.109 & 0.253 \\
& M+1SD & 0.246 & 0.044 & 0.159 & 0.332 \\
\hline
\end{tabular}

\section{Conclusions and Discussion}

Based on the background of the knowledge economy, this research constructs a model of the relationship between customer participation, knowledge integration, absorptive capacity and NPD performance, and tests the model and relevant hypotheses with the combination of large sample questionnaire survey to empirically analyze the mechanism of customer participation on knowledge integration and NPD performance. The main conclusions are as follows: First, customer participation has a significant positive impact on NPD performance. Second, knowledge integration plays an intermediary role between customer participation and NPD performance. Third, absorptive capacity positively moderates the relationship between knowledge integration and customer participation, but has no significant moderating effect on customer participation and NPD performance. A less significant reason may be that when the level of absorptive capacity is high, enterprises can acquire a large amount of external knowledge, but when the knowledge stock exceeds the capacity of the enterprise's management knowledge base, it will increase the risk of innovative knowledge sources and increase the management cost, thus the enhancement of absorptive capacity will weaken the transformation of customer knowledge into NPD performance.

The above research results enrich and expand the relevant results of the research on the relationship between customer participation and NPD performance and provide important practical significance to improve the success rate of NPD and promote high-quality development. First of all, enterprises should pay attention to and guide customers to participate in 
NSD activities, which can not only provide enterprises with external knowledge sources, but also help build good customer-enterprise relationships, promote the value co-creation process, and improve NSD performance. Secondly, given the mediating role of knowledge integration between customer participation and NPD performance, so enterprises need to continuously acquire and utilize external customer knowledge as well as transform, reorganize and integrate on the basis of existing knowledge resources to continuously increase the knowledge stock and thus improve NPD performance. Thirdly, absorptive capacity is an important force for enterprises to gain competitive advantage. Different enterprises have different abilities to acquire and absorb heterogeneous knowledge, and good absorptive capacity enables enterprises to quickly identify and absorb the required knowledge, thus enterprises can enhance their own absorptive capacity to improve the efficiency of knowledge integration and reduce the impact of knowledge asymmetry. Finally, although customer participation contributes to the improvement of corporate performance to a certain extent, companies with strong absorptive capacity should not overly rely on customer participation to improve NSD performance. Increased absorptive capacity will weaken the conversion of customer knowledge to NSD performance. At this time, enterprises should focus on the integration and utilization of acquired knowledge and existing knowledge to obtain the key knowledge required for innovation, so as to promote the smooth implementation of NPD activities.

Due to capacity constraints, there are still some limitations. First, the sample data are concentrated in high-tech enterprises in Wuhan-China Optics Valley, and there are limitations in the selection of regions and types of enterprises. Follow-up research can select sample data covering different regions and introduce industry differences indicators, discuss the impact of the interaction between enterprises and customers on NPD performance in the context of manufacturing servicing to draw more general conclusions. Second, this study develops a measurement scale based on the role played by customer participation. In the future, we can try to explore its effect on NPD performance from different stages of customer participation (such as the fuzzy front-end stage, product design stage, and launch test stage). Third, moderate customer participation can effectively improve NPD performance. This study explores the mediating effect of knowledge integration and the moderating effect of absorptive capacity. In the future, other variables can be further explored as a bridge between customer participation and NPD performance for further extend the findings of this study.

\section{Acknowledgements}

The authors would like to thank anonymous reviewers for their very helpful comments and useful suggestions. We would like to express our gratitude to all the firms, participants, and interviewees in this study. This study was supported by National Natural Science Foundation of China (NSFC, project grant No: 72072139), the Grant-in-Aid for Humanities \&
Social Science research foundation (project grant No: 19YJAZH03) from the Ministry of Education (MOE) of China, also Soft Science research foundation for technological innovation (project grant No: 2019ADC049) from S \& T Department of Hubei Province, and the S\&T innovative team project from Wuhan Textile University.

\section{References}

[1] Chesbrough, H., Lettl, C. \& Ritter, T. (2018). Value creation and value capture in open innovation. Journal of Product Innovation Management, 35 (6), 930-938.

[2] Blut, M., Heirati, N. \& Schoefer, K. (2020). The dark side of customer participation: when customer participation in service co-development leads to role stress. Journal of Service Research, 23 (2), 156-173.

[3] Li, Z., \& Yang, H. T. (2012). The impact of absorptive capacity, relationship learning and knowledge integration on the enterprise innovation performance: An empirical study on technology based SMEs. Science Research Management, 33 (01), 81-91. (In Chinese).

[4] Guo, J., Cheng, Y. C. \& Guan, K. Y. (2017). Influence of customer participation on NPD performance in the context of b2b: mediating effect of knowledge integration mechanism. Science \& Technology Progress and Policy, 34 (08), 106-111. (In Chinese).

[5] Nätti, S., Hurmelinna-Laukkanen, P. \& Johnston, W. J. (2014). Absorptive capacity and network orchestration in innovation communities: Promoting service innovation. Journal of Business \& Industrial Marketing, 29 (2), 173-184.

[6] Dong, B., \& Sivakumar, K. (2017). Customer participation in services: domain, scope and boundaries. Journal of the Academy of Marketing Science, 45 (6), 944-965.

[7] Morgan, T., Anokhin, S. A., Song, C. \& Chistyakova, N. (2019). The role of customer participation in building NPD speed capabilities in turbulent environments. International Entrepreneurship and Management Journal, 15 (1), 119-133.

[8] Carlson, J., Rahman, M., Voola, R. \& De Vries, N. (2018). Customer engagement behaviors in social media: capturing innovation opportunities. Journal of Services Marketing, 32 (1), 83-94.

[9] Zhang, J. \& Liao, X. W. (2020). Customer participation, knowledge sharing and new product development performance in virtual communities. Management Review, 32 (04), 119-133. (In Chinese).

[10] Salunke, S., Weerawardena, J. \& McColl-Kennedy, J. R. (2019). The central role of knowledge integration capability in service innovation-based competitive strategy. Industrial Marketing Management, 76 (20), 144-156.

[11] Grant, R. M. (1996). Prospering in dynamically competitive environments: Organizational capability as knowledge integration. Organization Science, 7 (4), 375-387.

[12] Yang, M. M. \& Yang, J. R. (2020). Boundary spanning search, knowledge integration and sustainable competitive advantage. Studies in Science of Science, 38 (04), 696-704. (In Chinese). 
[13] Ruiz, É., Brion, S. \& Parmentier, G. (2020). Absorbing knowledge in the digital age: the key role of integration mechanisms in the context of crowdsourcing for innovation. $R \& D$ Management, 50 (1), 63-74.

[14] Cohen, W. M. \& Levinthal, D. A. (1990). Absorptive capacity: A new perspective on learning and innovation. Administrative science quarterly, 35 (1), 128-152.

[15] Flor, M. L., Cooper, S. Y. \& Oltra, M. J. (2018). External knowledge search, absorptive capacity and radical innovation in high-tech firms. European Management Journal, 36 (2), 183-194.

[16] Jian, Z. Q., Zeng J. L. \& Liu, Y. (2018). Relationship between external organizational integration and new service development performance: a model of mediation moderated of absorptive capacity. Chinese Journal of Management, 15 (09), 1327-1336. (In Chinese).
[17] Dai, Z. H., Peng, Y. F., Ma, W. J. \& Zeng, S. X. (2014). A study on effect of customer participation on enterprise technological innovation performance towards NPD. Journal of Systems \& Management, 23 (06), 778-787. (In Chinese).

[18] Yi, Y. \& Gong, T. (2013). Customer value co-creation behavior: Scale development and validation. Journal of Business research, 66 (9), 1279-1284.

[19] Eslami, M. H., Lakemond, N. \& Brusoni, S. (2018). The dynamics of knowledge integration in collaborative product development: Evidence from the capital goods industry. Industrial Marketing Management, 75 (11), 146-159.

[20] Preacher, K. J. \& Hayes, A. F. (2008). Asymptotic and resembling strategies for assessing and comparing indirect effects in multiple mediator models. Behavior research methods, 40 (3), 879-891. 